\title{
Flipped Classroom Theories of Japanese Teaching
}

\author{
Yixing $\mathrm{Li}^{1}$, a \\ ${ }^{1}$ BOHAI University, China \\ ayxli2004@sina.com
}

Keywords: Flipped classroom, Japanese Teaching, Concepts, Teaching model

\begin{abstract}
Flipped classroom is through knowledge transfer and within the knowledge of the reverse arrangement, we changed the traditional role of teaching teachers and students to use classroom time and were re-planning, the realization of the traditional teaching model innovation. In the flipped classroom for learners to build a personalized collaborative learning environment, contribute to the formation of new learning culture. By surrounding the origin flipped classroom, the concept and characteristics of analysis, based on the inversion theory classroom, we construct a flip Japanese classroom teaching model, and analyzes the flip Japanese classroom challenges the process of facing the implementation, with a view to our Teaching for reference.
\end{abstract}

\section{Introduction}

Traditional teaching process typically includes knowledge transfer and within the knowledge of the two phases. Imparting knowledge is taught by teachers in the classroom to complete, within the knowledge of the needs of students in after-school through the job, operation or practice to complete [1]. On the flipped classroom, this form has been subverted by imparting knowledge of information technology supporting the completion of the class, knowledge is internalized by assisting in the classroom to help teachers and students accomplished, thus forming a flipped classroom. With the reversal of the teaching process, classroom learning process in all aspects also will be changed(shown as fig.1). The main case of the traditional classroom and flipped classroom each element of contrast, including:

Changing of Teachers roles. Flipped classroom so that teachers from the traditional classroom imparting knowledge into a learning facilitator and mentor. This means that the teacher is no longer a center of knowledge and interactive applications, but they are still students learn the main promoters [2]. Once students need guidance teachers will provide the necessary support to them. Since then, teachers become students' easy access to resources, use of resources, process information, the application of knowledge to the real situation in the scaffolding.

Changing student roles. With the development of technology, education has entered into a new era; an era of student self-knowledge can be extended. Educators can use wikis, blogs and other technological tools to efficiently provide students with rich learning resources, students can get the knowledge they need in a network resource. In technical support personalized learning, students become self-paced learners, they can control the learning time, learning the choice of location, you can control the learning content, learning capacity. However, in the flipped classroom, students are not entirely independent learning. Flipped classroom is dynamic and is highly involved in the classroom needs of students [1]. In technical support collaborative learning environment, students need repeated with classmates, teachers interact according to the learning content, to expand and create knowledge depth. Therefore, flipped classroom is a classroom to build depth of knowledge, student is the protagonist of the classroom.

Reallocation of classroom time. Flipped classroom of second core feature is to reduce the time teachers teach in the classroom, leaving students more time learning activities. These learning activities should be based on real life, real situations, and allows students to complete learning tasks in interactive collaboration [1]. The original content of classroom teaching to the next lesson, without reducing the amount of basic knowledge demonstrated on the basis of high school students enhance classroom interaction. Ultimately, the change will increase the students' understanding of the extent of the knowledge. In addition, when teachers based on performance evaluation, classroom interaction 
will become more effective. According to the evaluation feedback of teachers and students will be more objective understanding of their own learning, better control of their own learning.

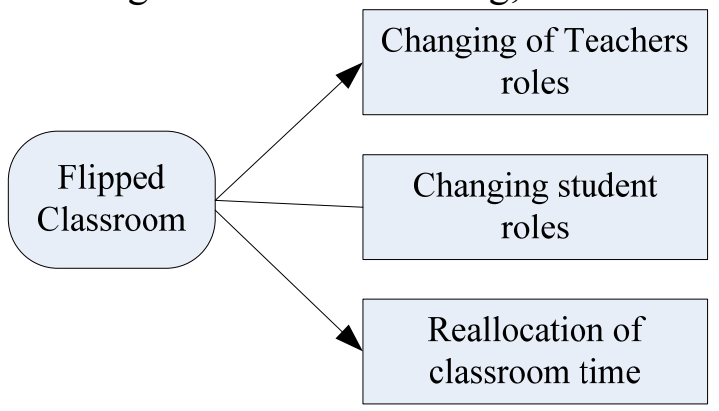

Fig.1 Changing of classroom learning process

\section{Flipped Classroom Teaching Model Design of Japanese Teaching}

Flipped classroom and realize the knowledge transfer within the knowledge of the upside. Will be taught in the traditional classroom knowledge transfer to complete before class, knowledge is internalized from the original after-school homework activities transferred to classroom learning activities (fig.1). Franklin College of Mathematics and Computing Science professor Robert Talbert in many courses (such as "the use of computer tools to solve the problem", "Linear Algebra") applied flipped classroom teaching mode and achieved good teaching results. After the accumulation of years of teaching, Robert Talbert summed up the implementation of structural flipped classroom model [2]. The model is described briefly flipped classroom in the main part of the implementation process, but applies its multi-disciplinary science class curriculum in favor of interoperability, for liberal arts courses need to be further improved.

Constructivist learning theory, systematic instructional design theory, the flipped classroom model-based professor Robert Talbert, the author build a more perfect flip Japanese classroom teaching model according to the connotation flipped classroom as well [3]. The teaching model is mainly composed of pre-class learning and classroom learning two parts. In both process, IT and learning activities are flipped classroom learning environment created by two powerful lever. Support and learning activities to ensure the smooth development of the construction and generate personalized collaborative learning environment.

Pre-class module design.Flip Japanese in the classroom, imparting knowledge is generally provided by the teacher instructional videos to complete [3]. Teaching video can be recorded by the Curriculum speaker teachers personally or over the network using excellent open educational resources.

Japanese teachers teaching their own video recording can be fully and Teachers set instructional objectives and teaching content coincide, while teachers can according to the actual situation of the students to explain the relevance of teaching content, and according to different classes of students to multi-version differences record instructional video. The availability of these advantages, self-recorded instructional video also gives teachers teaching technical and time challenges.

Classroom activities Module Design. One of the features Flip Japanese classroom is carried out on the basis of maximizing, continue to extend the classroom learning time to improve learning efficiency, the key is within the knowledge of how to accomplish through classroom activities designed to maximize [4]. Constructivists believe that the acquisition of knowledge in certain situations learners meaning construction process of realization through interpersonal collaboration activities. Therefore, teachers in designing classroom activities, should take full advantage of situation, cooperation, conversation and other factors into full play the subjectivity of students to complete the current internalize what they have learned (see fig.2). 


\section{Learning Pyramid}

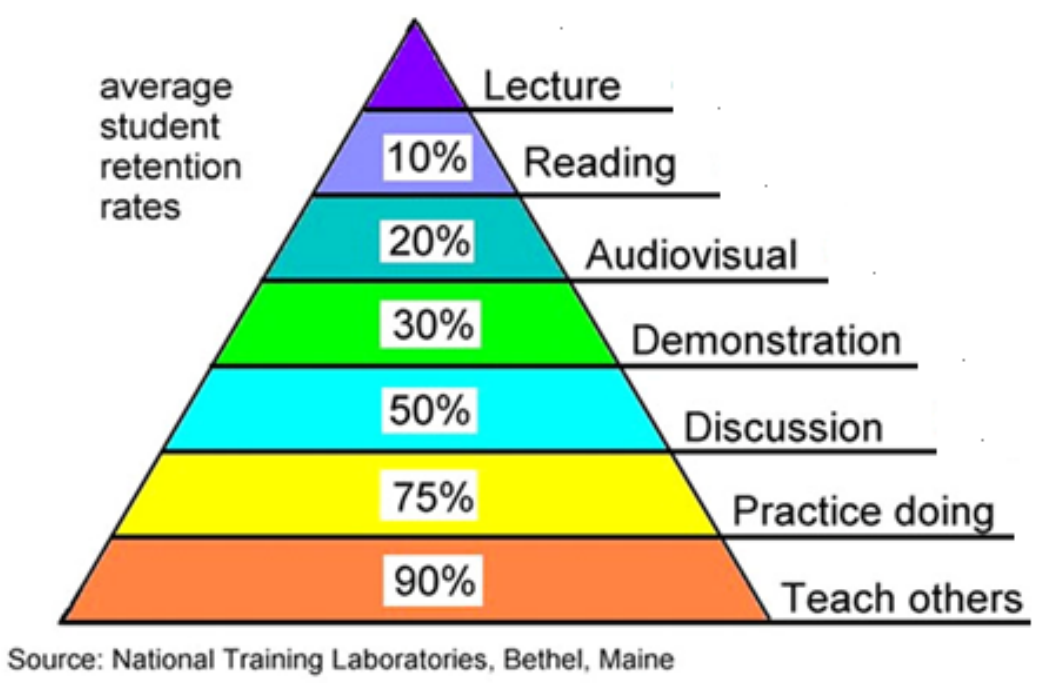

Fig.2 Flipped classroom learning pyramid

a. Identify problems. Teachers need to watch instructional videos based on course content and students before class practice raised questions, summed up some questions worth exploring. Students choose the appropriate topic based on understanding and interest inquiry. In this process, teachers should be targeted to guide students in selecting topics [4].

Depending on the selected group of Students, when the problem involves a broader and can be divided into several sub-problems, team members can follow the "Puzzle" Learning to explore learning. Each team member is responsible for a child to explore the issue, and finally the overall polymerization together for collaborative inquiry. When the problem involves a small, not easy to be divided, each team member can be an independent study of the issue, and finally explore collaboration.

b. Independent exploration.Independent learning ability is one of the important qualities of learners should possess. Individuals from a development perspective, the students are from dependence to independence process. Teaching wild country famous experts believe that students "independence" has four meanings [5]: (1) Each student is an independent person, student learning is their own thing, this is not a substitute teacher is not replaced. Teachers can allow students to read their own feelings of things, observation, analysis, reflection, and help them self sensible, to acquire knowledge; (2) are independent of each student teacher's mind, not to the teacher's will . Teachers want students to accept their teachings, first students should not exist as an objective in its own will as to transfer, as a person with independence to look at, so that their education to meet their actual situation; (3) each student has an independent claim, the learning process in their school is a separate and independent process for growing. (4) Each student (except for special reasons) have a very strong independent learning ability.

c. Collaborative Learning.Collaborative learning is the use of dialogue between individuals, discuss, debate and other forms fully demonstrated by the research questions to get way to achieve learning objectives [5]. In addition, the formation of collaborative learning students 'critical thinking and creative thinking, improve students' communication skills, self-esteem and mutual respect form the relationship between the individual, have a significant positive effect. Therefore, the classroom should be flipped Japanese interactive learning designed to enhance collaboration.

Japanese flipped classroom interactive activities, teachers need to capture the students to be dynamic and timely guidance. The Panel is an interactive course of basic building blocks, its interaction involving 2 or 2-5 people. Advantage flipped classroom environment group cooperation: everyone can participate in activities; and to allow and encourage students to low-risk, non-threatening way to participate meaningfully; may provide an opportunity for participants to communicate with their peers, and are free check the correctness of their own ideas; providing a variety of strategies to solve the problem, brainstorming. 
d. Achievements exchange.Students through independent exploration, collaborative learning after completion achievement highlights individual or group. Students need to be reported in the classroom, the exchange of learning experiences, to share the joy of success and the work produced [6]. The forms can be varied outcomes exchange, such as holding exhibitions, lectures, debates, and other small game.

In addition to reporting directly in the classroom, it can also flip the reporting process, the students in their spare their reporting process for video, uploaded to the network platform, teachers and students in reporting after watching the video, in class discussion and evaluation.

e. Feedback Assessment. Flip Japanese classroom assessment and evaluation system is completely different from the traditional classroom. In this teaching model, the evaluation should be completed by the experts themselves, academics, teachers, peers and learners. Flip Japanese classroom should not only focus on learning outcomes assessment, but also through the establishment of student learning archives, focusing on the evaluation of the learning process, truly quantitative evaluation and qualitative evaluation, formative assessment and summative evaluation, personal evaluation and the evaluation team, a good combination between self-assessment and evaluation of others [6]. Content evaluation of the issues involved choice, independent of the performance of the learning process, learning in the group's performance, study schedule, schedule, results and other aspects of expression and the results show. Evaluation of the results emphasize the students' knowledge and skills mastery, process evaluation emphasized that students in the experimental record, all kinds of raw data, activity $\log$ form, questionnaire, interview table, learning experience, reflect on the contents of the diary and other performance .

\section{Conclusion}

Using flipped classroom teaching mode in Japanese courses allow students to relatively complex step more skills repeatedly watching video, to understand the effect of memory. To avoid the traditional IT classroom teachers operating demonstrate again the blind imitation of the students when the students hands-on due to the limited memory capacity and the emergence of let. Students With a flipped classroom model, before class to master basic skills rate has reached a certain percentage, and links to the students left the classroom enough time for students to self-inquiry and cooperative learning. So this part of the students' learning ability can help raise get deeper and develop a wide range, but also promote the formation of Japanese language teaching higher-order capabilities.

\section{References}

[1] Zh.Y.Guo, Y.J. Zhang, Perspective of "flipped classroom",Primary and Secondary Schools IT education, 2012,pp. 21-27.

[2] G. Yang, T. Chen, Ten "flipped classroom" wonderful case,Primary and Secondary School Information Technology Education, 2012, pp. 65-69.

[3] K.Ke, Theoretical basis to reform the traditional teaching,Educational research, 1997, pp. 33-36.

[4] W.S. Y, Brief Discussion subjectivity and self-learning, Education, 2001, pp.8-12.

[5] J. Xiong, Teacher Notes "flip" the language classroom, Primary and Secondary School Information Technology Education, 2014, pp.91-95.

[6] L. Wang, J. Wang, Experience Review MIT OCW use project, Open Education Research, 2005, pp.43-48. 